\title{
Health Promoting Leadership: The Mediating Role of an Organizational Health Culture
}

\author{
Jochen Gurt and Gabriele Elke \\ Ruhr-University at Bochum, Universitätsstraße 150, 44780 Bochum, Germany \\ Tel.: +49-234-32-24608 \{Jochen Gurt\} \\ jg@auo.psy.rub.de
}

\begin{abstract}
Drawing from the findings within the safety literature, the present study identifies the effects of leadership on an organizational health culture and strain. The importance of leadership for the development of a corporate health culture is demonstrated as well as the positive effect of health culture on employee strain level. Empirical data from a longitudinal study in the German tax administration is presented. Leadership has a positive impact on the development of a corporate health culture, which in turn reduces employees' strain level. Discussion addresses the similarities of health and safety leadership regarding effects and mediating processes.
\end{abstract}

\section{Introduction: From Health and Safety Management to Worksite Health Promotion}

Health and safety in organizations have often been treated as a single subject in the literature [28]. In Germany the classical domain, which dealt with employee health, has been that of occupational health and safety management. Primary focus of this approach was to protect workers and employees health from dangers and hazards originating from work or the working environment (e.g. accidents, contamination). A lot of research concerning health and safety management was carried out in production sites, power plants and military settings, where technical and organizational configurations served as barriers for the protection of employee health. A second approach to employee health is worksite health promotion [10]. Studies here take place more often in office-settings. They build on the findings of health and safety management, but shifted the focus to employee health: Along with the World Health Organization (WHO) health is understood as "a state of complete physical, mental and social wellbeing" [25], health promotion as a "process of enabling people to increase control over, and to improve their health" [25]. Worksite health promotion, particularly coping with stress therefore rests on a Job Demands-Resources Model JDR, [4], which draws from the salutogenetic approach of Antonovsky [1]. At the core of this model is the idea that employee health (and strain) is affected by two factors: First, job demands originating from the task, the workplace, the organization or the physical surroundings, which can induce strains and may have a negative effect on health and well-being. Second, job 
resources (physical, social, psychological and organizational job characteristics), which have a buffering effect within this process by reducing job demands and strains as well as stimulating personal growth and development. Resources are categorized into internal (personal) and external. Personal resources are personality characteristics or qualifications like coping strategies, attribution styles or skills. External resources refer to the organizational and off-the-job settings and include amongst others factors of workplace design and work organization, work autonomy, social support from friends, family, but also colleagues and supervisors. Following an organizational management approach, top-management commitment and leadership (supervisor) support are seen as key resources for successful worksite health promotion [29]. Leadership qualities have shown to be an important explanatory psychosocial factor with regard to sick leave, employee health and well-being [8]. In addition to their direct influence on employee health, leaders are also seen as promoters of a supportive organizational climate and culture. Support of this view comes from findings within the safety promotion domain [31], [33]. Safety climate/ culture are seen as important outcomes of all health and safety initiatives [7]. However, empirical studies identifying leadership behaviors and culture together influencing health related variables within worksite health promotion are rare. The present study tries to empirically support the claim of the prominent role of leadership and organizational health culture within clerical work. Data is presented from a longitudinal study in the German tax administration.

\section{The Role of Leadership and Organizational Culture in Safety and Health Management}

The impact of leaders on safe and healthy behavior of employees is twofold: First, management and leaders (to some extent) shape organizational processes and management sub-systems (e.g. human resource management). Through these systems they exert control over a variety of health-related physical and psycho-sociological characteristics of work and the working environment e.g., the individual workload and amount of responsibilities, technical equipment, but also the organization of work like working hours or breaks [6]. As shown, within the JDR model these factors impose demands upon the employee, which in turn could lead to strains [4]. Numerous studies underscore this relationship (e.g. review by Sonnentag \& Frese, [19]). It could also be demonstrated that leadership has an impact on the design of these work characteristics, and acts as a buffering resource for health relevant outcomes [16], [26]. In these studies work characteristics can also be regarded as mediators through which leadership behaviors affect employee outcomes. For example the study by Wilson et al. [26] linked organizational attributes (e.g. policies and practices to facilitate employees' abilities to balance work and non-work issues) to climate (which included involvement with supervisor) and job design, which comprised workload, work scheduling, and physical work conditions.

Second, leaders also influence safety behavior and health of employees through day-to-day direct and personal interaction and communication. Two distinct ways of influence can be identified: 
1. The direct approach to immediate modification of behavior functions via behavior control through training, personnel appraisal and reward systems. Behavior control has its origins in the operant perspective of role behavior and the connected $\mathrm{ABC}$ framework (i.e. antecedents-behavior-consequences; Stajkovic \& Luthans,[21]. Mainly two kinds of antecedents were used - goal setting and training - and three kinds of consequences, namely feedback, incentives, and social recognition. Antecedents have mostly been used in combination with positive consequences of some kind [9]. Modification of safety behavior by the ABCframework received impressive empirical support in particular on individual and group level [7], [22].

2. The second (indirect) influence of leadership interaction on health and safety behavior is through mediating variables. Strong evidence comes here from safety literature for the important role of safety climate and culture as important mediating variables [12]. Drawing from social cognitive learning theory, employee behavior is (among other factors) a function of perceived behavior of their environment. Leaders serve as role-models. Norms and values develop from this learning process, which may serve as leadership substitutes to guide employee behavior. While also operant and transactional leadership behaviors are expected to have a beneficial effect on safety culture [7], ethical and transformational leadership seem to contribute even more to a supportive safety culture. These leadership styles rest on value-based behavior, charisma and authenticity of the leader. Various studies confirm their direct positive impact on organizational safety culture/ climate and safety [3], [14], [32].

However, reverse effects or additional mediators between leadership and safety like safety consciousness, safety communication, safety programs and initiatives as well as safety commitment have been examined. Other studies show even moderating effects of safety climate, safety priority or transformational leadership. In sum, the studies draw attention to the fact that leadership is a crucial variable to improve workplace safety. Safety climate is the most important mediator, but the mechanisms behind the effects are highly complex and yet not fully understood.

Concerning health promotion, the direct leader employee interaction is also seen to be crucial for the success of organizational health promotion programs [29]. So far, only a few studies within the health promotion literature have addressed this issue. One study on a health promotion program on tobacco and alcohol use in the armed forces reported that successful implementation and retention of this program was largely dependent on leadership engagement for the program [27]. Another indication comes from a Swedish study at municipally human service organizations [8]. The impact of workplace health promotion initiatives was dependent on various leadership behaviors, such as participation, the attitude towards the cause of sick leave as well as respect, trust and open discussion. This finding also underpins the importance of a participative approach, which is seen as an important prerequisite for successful health [19], [28]. Westermayer and Stein [24] identified reliability and trust as the core factors of leadership influencing stress level and absenteeism. Transformational and ethical leadership, which rest on value-based behavior, charisma and authenticity, have proven to have a direct positive impact on the perception of work characteristics and employee well-being (e.g. Nielsen et al.[16] Arnold et al., [2]) and are negatively 
related to stress symptoms and burnout (e.g. Hetland, Sandal, \& Johnsen, [13]; Sosik $\&$ Godshalk,[20]). In some studies also reciprocal effects were found, indicating that well-being of employees at the first time of measurement had an effect on leadership behavior measured at the second point of time. This indicates that employee wellbeing (and probably behavior) also impacts leader behavior [16],[23].

Summarizing the findings, culture is seen as a prominent mediator in both health and safety leadership in order to increase safety performance and health. Within health promotion, engagement of the leader for health promotion seems to be of relevance for the success of health initiatives. While in the safety literature especially the studies of Zimolong and Elke [29] and Zohar and colleagues (e.g. Zohar \& TenneGazit, [32]) addressed the issue of the importance of safety climate as a mediating variable, there are only few studies identifying leadership behaviors and culture together influencing health related variables. Longitudinal studies separating concurrent and long-term effects are also rare (Nielsen et al., [16]). Based on the empirical findings in the safety literature, this analysis aims to identify the impact of leadership on strain in a longitudinal design, including corporate health $(\mathrm{OH})$ culture as a mediating organizational resource.

\section{Method}

\subsection{Design and Participants}

The sample consisted of 265 employees in four local tax offices in the German tax administration in North Rhine-Westfalia. Tax office size ranged from 188-293 employees. The 265 respondents represented $31.4 \%$ of all 982 employees in the four locations. Survey questionnaires were administered online during a two-week period with a six-month interval between the two sampling points. Questionnaire responses were completely anonymous, and participation was encouraged via emails but voluntary. Frequency of participation at $\mathrm{t}_{1}$ was 487 and 350 at $\mathrm{t}_{2}$. Participation rates in the tax offices ranged from $51.3 \%$ to $65.2 \%$, at $\mathrm{t}_{1}$ from $36.5 \%$ to $53 \%$ at $\mathrm{t}_{2}$. Individuals were tracked by an individual code. In the analysis only data from employees were included, who responded at both sampling points, which led to the reduced sample size for the analysis of 265 employees. Socio-demographic data showed that $4.9 \%$ were younger than $30,68.8 \%$ between 30 and 50 years, and $28.3 \%$ older than 50 years. About $72.1 \%$ of participants were female and $57.4 \%$ employed full-time. These figures mirror the actual distribution of the socio-demographic profile in the four tax offices.

\subsection{Instruments and Measures}

Study participants were provided an inventory comprising different questionnaires. Strain captured the level of irritation of the individual employee. It was measured using three items $(\alpha=.71 / .76)$ from the irritation scale by Mohr et al. [15]. A sample item reads "I have problems to relax, even in my leisure time". 
Healthy leadership behavior and cultural scales are drawn from a short version of the Organizational Health and Safety (OHS) questionnaire (FAGS, [11] in press). The Organizational Health $(\mathrm{OH})$ questionnaire follows the Job Demands-Resources Model (JDR) and addresses three different areas: Demands, individual resources of the employee, external resources provided by the organization, including leadership performance and assessment of $\mathrm{OH}$ culture.

$\mathrm{OH}$ culture refers to the degree to which "health" is already integrated in the organizational norms and values. It was measured with two items $(\alpha=.64 / .66)$, such as "Health initiatives in my organization are either insufficient or inadequate" (reverse coded).

Leadership behavior is measured in terms of general healthy leadership behaviors (HLB) and the engagement in health promotion of the leader (EHP).While HLB captures routine behaviors that have shown to have beneficial effects on employee health and well-being, such as setting objectives, giving feedback and recognition, employee participation and information ( 8 items, $\alpha=.87 / .88$, sample item: "My achievements are recognized by my supervisor"), EHP specifically captures the degree of engagement of the leader regarding health promotion ( 7 items, $\alpha=.91 / .92$, sample item „My supervisor asks me to contribute my experiences to the implementation of the health project"). These scales are not regarded as leadership styles or types, but rather as an index for a set of leadership behaviors that have been identified to be related to health outcomes in the past. Exploratory factor analysis yielded the two main factors HLB and EHB, extracting 64\% of the variance. Confirmatory factor analysis revealed a deeper second-order factor structure with the two factors each having two sub-factors: relationship and performance orientation, $\chi^{2}$ (101, $\mathrm{N}=265)=333.5 ; \mathrm{GFI}=.92 ; \mathrm{CFI}=.94 ; \mathrm{RMSEA}=.069$. All factor loading were psychological substantial (>.30) except for one item, which was dropped from the scale. For the further analysis we used the second-order factors without taking into account the particular sub-orientation.

Employees were asked to state their degree of agreement to various statements. Scales ranged from 1 to 5, 1 indicating "totally untrue" and 5 "exactly true".

\subsection{Computational Methods}

In order to test concurrent and time-lagged direct and mediated effects, structural equation modeling (SEM) with manifest variables was applied using AMOS 16. Three different models were tested. The first model (M1) assumed full-mediation of the effect of EHP and HLB on strain (irritation) through $\mathrm{OH}$ culture. Synchronous mediation effects at each point of time were included as well as time-lagged mediation effects, i.e. that EHP/ HLB at $t_{1}$ influenced $\mathrm{OH}$ culture at $t_{2}$. The second model (M2) assumed only partial-mediation and in addition to the mediated effects allowed for direct effects. The third model (M3) integrated the findings of Van Dierendonck et al. [23] and allowed for reciprocal effects of irritation at $t_{1}$ on leadership variables behavior at $\mathrm{t}_{2}$. 


\section{Results}

Table 1 shows the descriptive values and correlations among all study variables.

Table 1. Means, standard deviations, alphas, and correlations among study variables

\begin{tabular}{|c|c|c|c|c|c|c|c|c|c|}
\hline \multirow{2}{*}{\multicolumn{2}{|c|}{ Scale (\# of items) }} & \multicolumn{2}{|c|}{ Means } & \multicolumn{2}{|c|}{ SD } & \multirow{2}{*}{1} & \multirow{2}{*}{2} & \multirow{2}{*}{3} & \multirow{2}{*}{4} \\
\hline & & $\mathrm{t}_{1}$ & $\mathrm{t}_{2}$ & $\mathrm{t}_{1}$ & $t_{2}$ & & & & \\
\hline 1 & $\begin{array}{l}\text { Healthy Lead- } \\
\text { ership Behavior } \\
(\text { HLB }, 8)\end{array}$ & 3.14 & 3.15 & $(.81)$ & $(.83)$ & $.87 / .88$ & $.656 * *$ & $.227 * *$ & $-.137 *$ \\
\hline 2 & $\begin{array}{l}\text { Engagement for } \\
\text { Health Pro- } \\
\text { motion (EHP, 7) }\end{array}$ & 2.17 & 2.23 & $(.89)$ & $(.94)$ & $.630 * *$ & $.91 / .92$ & $.310 * *$ & -0.041 \\
\hline 3 & $\begin{array}{l}\mathrm{OH} \\
\text { Culture (2) }\end{array}$ & 3.30 & 3.37 & (1.00) & $(.98)$ & $.264 * *$ & $.307 * *$ & $.66 / .64$ & $-.215 * *$ \\
\hline 4 & $\begin{array}{l}\text { Strain/ } \\
\text { Irritation (3) }\end{array}$ & 2.77 & 2.65 & $(.88)$ & $(.88)$ & $-.194 * *$ & -0.065 & $-.171 * *$ & $.71 / .76$ \\
\hline
\end{tabular}

${ }^{+}$Cronbach's Alphas are on the diagonal, correlations above represent $\mathrm{t}_{2}$ data, below $\mathrm{t}_{1}$ data; ${ }^{*} \leq .05,{ }^{* \star} \leq .01,{ }^{* \star *} \leq .001$

Table 2. Fit indices for longitudinal models testing for mediation

\begin{tabular}{|c|c|c|c|c|c|c|c|}
\hline $\begin{array}{l}\text { Mod- } \\
\text { els }\end{array}$ & $\chi^{2}$ & $\begin{array}{c}\Delta \chi^{2} \\
\left(\mathrm{df}_{\Delta, \mathrm{p}}\right)\end{array}$ & $\begin{array}{c}\mathrm{NC} \\
\left(\chi^{2} / \mathrm{df}\right)\end{array}$ & GFI & AGFI & CFI & RMSEA \\
\hline M 1 & $\begin{array}{l}13.819 \\
(\mathrm{df}=13 ; \\
\mathrm{p}=.387)\end{array}$ & & 1.06 & .987 & .963 & .999 & .015 \\
\hline M 2 & $\begin{array}{c}9.053(\mathrm{df}=8 ; \\
\mathrm{p}=.338)\end{array}$ & $\begin{array}{c}4.76 \\
\left(\mathrm{df}_{\Delta}=5 ; \text { n.s. }\right)\end{array}$ & 1.13 & .992 & .962 & .998 & .022 \\
\hline M 3 & $\begin{array}{c}6.274(\mathrm{df}=5 ; \\
\mathrm{p}=.280)\end{array}$ & $\begin{array}{c}7.58 \\
\left(\mathrm{df}_{\Delta}=2 ; \text { n.s. }\right)\end{array}$ & 1.25 & .994 & .958 & .999 & .031 \\
\hline
\end{tabular}

Means of all scales are rather stable over time, exhibiting only marginal changes. HLB means exceed at both times EHP. With means of 3.14 and 3.15 HLB lies slightly above the scale mean, while EHP lies clearly below (2.17/ 2.23). At both sampling points $t_{1}$ and $t_{2}$ correlations among the variables are as expected, indicating positive relationships between leadership and $\mathrm{OH}$ culture. Negative correlations are found for irritation and the remaining scales. The only correlation that neither became significant at $t_{1}$ nor $t_{2}$ is between EHP and irritation. Table 2 lists the fit indices for each model derived from the SEM. Although all models indicate satisfactory fit, M1 (as indicated by the RMSEA and standardized chi-square (NC)) best fits the empirical data indicating that the effects of leadership on irritation are fully mediated via $\mathrm{OH}$ culture. Models M2 and M3 do not help the model indicated by a non-significant 
change of Chi-Square ruling out reciprocal and direct effects. Coefficients of the added paths in M2 and M3 also fail to reach significance with the exception of HLB, which shows a significant direct relationship with irritation of -.11 (but only at $t_{1}$ ). Figure 1 shows the M1 model with standardized path coefficients (non-significant paths are indicated by dotted lines). Stability paths $\left(t_{1}-t_{2}\right)$ of the measures indicate that rank order of subjects in respect of the measures remains rather stable (coefficients between .61 and .74). The two leadership scales (HLB and EHP) correlate around .60, indicating that engagement for health promotion (EHP) often comes together with (routine) healthy leadership behavior (HLB).

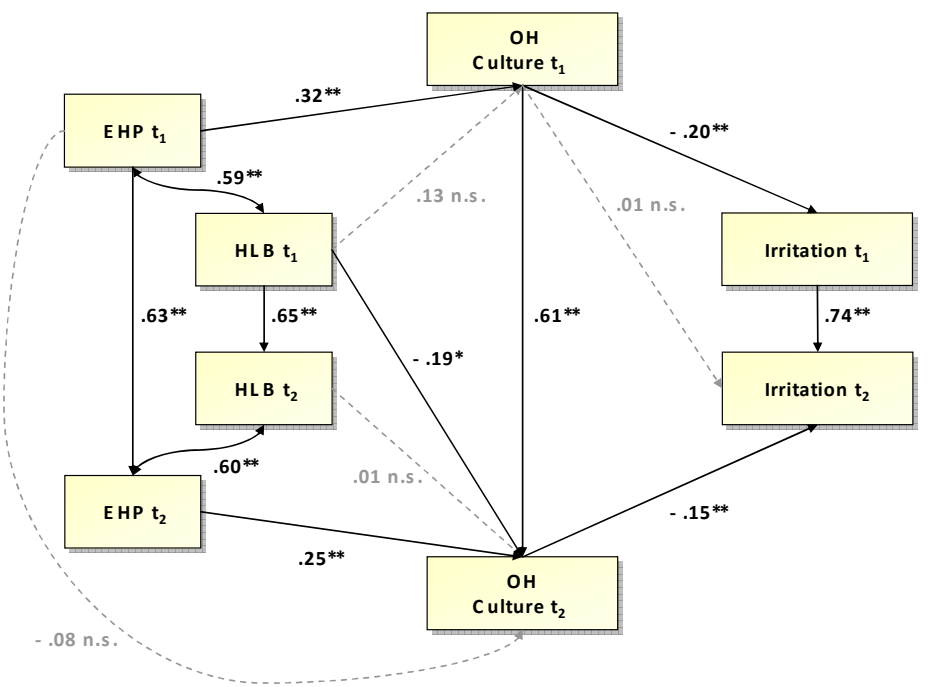

Fig. 1. Standardized maximum likelihood estimates for model M1

For the impact of $\mathrm{OH}$ culture on irritation we only find concurrent effects at $\mathrm{t}_{1}$ and $t_{2}$, but no lagged effects from $t_{1}$ to $t_{2}$. EHP is a strong predictor of $\mathrm{OH}$ culture at both $\mathrm{t}_{1}$ (.32) and $\mathrm{t}_{2}(.25)$, while we do not find this effect for HLB concerning the routine leadership tasks. What we do find is a surprisingly negative time-lagged effect of -.19 from $\mathrm{HLB}$ at $\mathrm{t}_{1}$ on $\mathrm{OH}$ culture at $\mathrm{t}_{2}$.

\section{Discussion}

The aim of the study was to identify the role of leadership and $\mathrm{OH}$ culture with regard to their impact on employee strain level within the context of health promotion in a clerical setting.

Considerable previous research had supported the association between transformational leadership behavior and various measures of strain, health and well-being (e.g. Nielsen et al. [16]). This study has given special attention to the specific engagement of the leader in health promotion. The results indicate that indeed the special leader engagement has a beneficial effect on employee strain level via higher 
values of corporate health culture. Culture works as a mediator for the beneficial effects of leadership, backing the claims within health promotion of corporate health culture being a central success factor [29].

Routine leadership behaviors (HLB) do not contribute to an $\mathrm{OH}$ culture, which indicates that employees did not attribute "good" general leadership behavior with underlying organizational values concerning health. In order to contribute to the perception of a supportive $\mathrm{OH}$ culture the leader has to show his specific engagement for health promotion. Correlations indicate a significant negative relationship with strain (irritation), which is partly supported by the significant effect found in M2. This hints in the direction that such leadership behaviors (like giving feedback and setting objectives) should either have a direct influence on strain or be mediated by other variables, e.g. lower levels of role ambiguity [17].

Effects seem to be rather concurrent. Except for the contra-intuitive effect of HLB, no time-lagged effect of leadership behavior on $\mathrm{OH}$ culture is found, which makes it impossible to resolve the question of causality. In this study, it seems to be the actual behavior of the leader at one point of time, which influences perceptions of culture. Also it is the "current perception of health culture", which leads to lower values of strain. Perceptions of culture at $t_{1}$ are irrelevant for level of strain at $t_{2}$.

The results of this study mirror the findings in the domain of safety culture, where leadership is an important predictor of safety culture (e.g. Zohar \& Tenne-Gazit, [32]). Irrespectively from the domain (health promotion or safety) leaders serve as role models and their engagement in the respective domain seems to contribute a great deal to the development of the respective culture.

One limitation of the study might be the short time-lag between the two measurements. In the six-month study interval, long-term effects are not really captured by the study. There might also be seasonal effects, as workload within the tax administration is known to be seasonal. This indicates a confounding variable, which was not integrated in the model. Due to the missing time-lagged effects, no inferences on causality between the constructs can be made; all relationships might be of a rather reciprocal nature. Leadership might also be influenced by $\mathrm{OH}$ culture. In addition to that, there is an unresolved debate (also in safety and health management science) if the culture or the climate of an organization can be inferred from psychometric measures like a questionnaires [12], [18]. Nevertheless, it is widely agreed that both constructs serve as core indicators for safety and health within an organization [7], [28].

Practical implications from this study are that first by developing a visible $\mathrm{OH}$ culture the strain impact on employees can be reduced. Second, in order to establish an $\mathrm{OH}$ culture, the support of leadership should be ensured as they have a strong influence on the creation and development of a corporate health culture. Supervisors act as role models and should be regarded as a cornerstone for success of organizational health promotion activities. Therefore organizational health promotion practitioners should ensure that leaders are willing to assume responsibility, have the necessary qualification and play an active part within the process. In this context it is not sufficient that leaders have the general qualification for "good" leadership behavior; they also need to be aware of their function as role models and have the adequate strategies to show their willingness to take over responsibility for their subordinates health and safety. Only then will they be able to create a beneficial climate or culture. Regarding this issue healthy leadership and safety leadership seem to rely on comparable mechanisms. 


\section{References}

1. Antonovsky, A.: Unraveling the mystery of health. How people manage stress and stay well. Jossey-Bass, San Francisco (1987)

2. Arnold, K.A., Turner, N., Barling, J., Kelloway, E.K., McKee, M.C.: Transformational Leadership and Psychological Well-Being: The Mediating Role of Meaningful Work. Journal of Occupational Health Psychology 12(3), 193-203 (2007)

3. Barling, J., Hutchinson, I.: Commitment vs. controll-based safety practices, safety reputation, and perceived safety climate. Canadian Journal of Administrative Sciences 17, 76-84 (2000)

4. Bakker, A.B., Demerouti, E., Euwema, M.C.: Job Resources Buffer the Impact of Job Demands on Burnout. Journal of Occupational Health Psychology 10(2), 170-180 (2005)

5. Böhnisch, W.R., Krennmair, N., Stummer, H. (eds.): Gesundheitsorientierte Unternehmensführung. Eine Werteperspektive [Health-oriented Management. A value based perspective]. DUV, Wiesbaden (2006)

6. Cox, T., Leather, P., Cox, S.: Stress, health and organizations. Occupational Health Review, 13-18 (February/March 1990)

7. DeJoy, D.M.: Behavior change versus culture change: Divergent approaches to managing workplace safety. Safety Science 43, 105-129 (2005)

8. Dellve, L., Skagert, K., Vilhelmsson, R.: Leadership in workplace health promotion projects: 1- and 2-year effects on long-term work attendance. The European Journal of Public Health 17(5), 471-476 (2007)

9. Geller, E.S.: Actively caring for occupational safety: Extending the performance management paradigm. In: Johnson, C.M., Redmon, W.K., Mawhinney, T.C. (eds.) Handbook of organizational performance. Behavior analysis and mangement, pp. 303-326. Haworth, New York (2001)

10. Goetzel, R.Z., Ozminkowski, R.J.: The health and cost benefits of work site healthpromotion programs. Annu. Rev. Public Health 29, 303-323 (2008)

11. Gurt, J., Uhle, T., Schwennen, C.: Fragebogen zum Arbeits- und Gesundheitsschutz - Betriebliche Gesundheitsförderung [Health and Safety Management Questionnaire - Organizational Health Promotion]. In: Sarges, W., Wottawa, H. (eds.) Handbuch wirtschaftlicher Testverfahren, Pabst, Lengerich (in press)

12. Guldenmund, F.W.: The nature of safety culture: A review of theory and research. Safety Science 34, 215-257 (2000)

13. Hetland, H., Sandal, G.M., Johnsen, T.B.: Burnout in the information technology sector: Does leadership matter? European Journal of Work and Organizational Psychology 16(1), 58-75 (2007)

14. Hofmann, D.A., Morgeson, F.P.: The role of leadership in safety. In: Barling, J., Frone, M.R. (eds.) The Psychology of Workplace Safety, pp. 159-180. American Psychological Assoc., Washington (2004)

15. Mohr, G., Müller, A., Rigotti, T., Aycan, Z., Tschan, F.: Concerning the Structural Equivalency of Nine Language Adaptations of the Irritation Scale. European Journal of Psychological Assessment 22(3), 198-206 (2006)

16. Nielsen, K., Randall, R., Yarker, J., Brenner, S.-O.: The effects of transformational leadership on followers' perceived work characteristics and psychological well-being: A longitudinal study. Work \& Stress 22(1), 16-32 (2008)

17. O'Driscoll, M.P., Beehr, T.A.: Supervisor behaviors, role stressors and uncertainty as predictors of personal outcomes for subordinates. Journal of Organizational Behavior 15(2), 141-155 (1994) 
18. Ribisl, K.M., Reischl, T.M.: Measuring the climate for health at organizations: Development of the worksite health climate scales. Journal of Occupational Medicine 35, 812-824 (1993)

19. Sonnentag, S., Frese, M.: Stress in organizations. In: Borman, W.C., Ilgen, D.R., Klimoski, R.J. (eds.) Handbook of Psychology, Industrial and Organizational Psychology, pp. 453-491. J. Wiley \& Sons, Hoboken (2003)

20. Sosik, J.J., Godshalk, V.M.: Leadership styles, mentoring functions received, and jobrelated stress: A conceptual model and preliminary study. Journal of Organizational Behavior 21, 365-390 (2000)

21. Stajkovic, A.D., Luthans, F.: Behavioral management and task performance in organizations: Conceptual background, meta-analysis, and test of alternative models. Personnel Psychology 56, 155-194 (2003)

22. Tuncel, S., Lotlikar, H., Salem, S., Daraiseh, N.: Effectiveness of behaviour based safety interventions to reduce accidents and injuries in workplaces: critical appraisal and metaanalysis. Theroretical Issues in Ergonomics Science 7(3), 191-209 (2006)

23. Van Dierendonk, D., Haynes, C., Borril, C., Stride, C.: Leadership behavior and subordinate well-being. Journal of Occupational Health Psychology 9, 165-175 (2004)

24. Westermayer, G., Stein, B.: Produktivitätsfaktor Betriebliche Gesundheit [Productivity factor: Organizational Health], Göttingen, Hogrefe (2006)

25. WHO, http://www.who.int/about/definition/en/print.html, http://www. who.int/about/definition/en/print.html

26. Wilson, M.G., DeJoy, D.M., Vandenberg, R.J., Richardson, H.A., McGrath, A.L.: Work characteristics and employee health and well-being: Test of a model of healthy work organization. Journal of Occupational an Organizational Psychology 77, 565-588 (2004)

27. Whiteman, J.A., Snyder, D.A., Ragland, J.J.: The Value of Leadership in Implementing and Maintaining a Successful Health Promotion Program in the Naval Surface Force, U.S. Pacific Fleet. American Journal of Health Promotion 15(6), 437-440 (2001)

28. Zimolong, B., Elke, G.: Occupational Health and Safety Management. In: Salvendy, G. (ed.) Handbook of Human Factors and Ergonomics, pp. 673-707. Wiley, New York (2006)

29. Zimolong, B., Elke, G.: Die erfolgreichen Strategien und Praktiken der Unternehmen [The successful strategies and practices of enterprises]. In: Zimolong, B. (ed.) Management des Arbeits- und Gesundheitsschutzes - Die erfolgreichen Strategien der Unternehmen, pp. 235-268. Gabler, Wiesbaden (2001)

30. Zohar, D.: The influence of leadership and climate on occupational health and safety. In: Hofmann, D.A., Tetrick, L.E. (eds.) Health and safety in organizations: A multi-level perspective, pp. 201-230. Jossey-Bass, San Francisco (2003)

31. Zohar, D.: The effects of leadership dimensions, safety climate, and assigned priorities on minor injuries in work groups. Journal of Organizational Behavior 23, 75-92 (2002)

32. Zohar, D., Tenne-Gazit, O.: Transformational Leadership and Group Interaction as Climate Antecedents: A Social Network Analysis. Journal of Applied Psychology 93(4), 744-757 (2008)

33. Zohar, D., Luria, G.: The use of supervisory practices as leverage to improve safety behavior: A cross-level intervention model. Journal of Safety Research 34, 567-577 (2003) 